\title{
Rationale of Unfractionated heparin during elective Coronary Angiography
}

\author{
Malla R, ${ }^{1}$ Sharma R, ${ }^{1}$ Rauniyar B, ${ }^{1}$ KC MB, ${ }^{1}$ Maskey A, ${ }^{1}$ Joshi D, ${ }^{1}$ Hamal S 1 \\ ${ }^{1}$ Department of Cardiology, Shahid Gangalal National Heart Center, Bansbari, Kathmandu, Nepal.
}

\begin{abstract}
Background: Unfractionated heparin (UFH) has been conventionally used during coronary angiography (CAG). Whether to use unfractionated heparin or not, has been unanswered.

Methods: Hundred patients who underwent CAG through femoral route were assessed. CAG was performed without using unfractionated heparin and embolic or thrombotic event and vascular complications were observed during and after procedure.

Results: The right femoral approach was used in $92 \%$ of cases and the left in $8 \%$. Those patients who underwent radial route were excluded. Male (65\%) were exceeded the female and smoking (50\%) was the major predisposing factor. There were no embolic or thrombotic event and vascular complications such as bleeding, heamatoma, pseudoaneurysm formation, A-V fistula and retroperitoneal bleeding during or after procedure.

Conclusions: Routine elective CAG have shown no significant complication during or after the procedure without UFH.

Key words: angiography, coronary angiography, unfractionated heparin
\end{abstract}

\section{INTRODUCTION}

Coronary artery disease (CAD) remains the leading cause of death in the Western world. ${ }^{1}$ An estimated 17.5 million people died from cardiovascular disease in 2007, representing $30 \%$ of all global deaths. Of these deaths, 7.6 million were due to $C A D$ and 5.7 million due to stroke. About $80 \%$ of these deaths occurred in low- and middle-income countries. If current trends are allowed to continue, by 2015 an estimated 20 million people will die from cardiovascular disease. ${ }^{1}$ It is also becoming the leading cause of death in south Asia and account for $27 \%$ of all death in the WHO South-East Asia Region (SEAR). ${ }^{2}$ The gold standard test for the diagnosis of CAD is coronary angiography. ${ }^{3}$ Unfractionated heparin (UFH) has been conventionally used during coronary angiography (CAG). ${ }^{4}$ However, no data is available for the dosage required. Although there have been significant improvements in catheter dimensions, vascular complications are still frequent with the femoral route, particularly in obese patients, aortoiliac disease, or where potent anticoagulants or thrombolytics are used. ${ }^{5}$ Such complications result in prolonged hospital stay, increased need for transfusion and also prevent early ambulation. ${ }^{6}$ So use of UFH during routine elective CAG may increase the incidence of vascular complications such as bleeding, heamatoma, pseudoaneurysm formation, A$\checkmark$ fistula and retroperitoneal bleeding.

\section{METHODS}

This observational study enrolled 100 patients who underwent elective coronary angiography between December 2008 and May 2009 in at Shahid Gangalal National Heart Center, Bansbari, Bansbari. At admission, a standardized data collection form was filled out by the duty physician. Demographic information, CAD risk factors, and clinical signs were collected. Informed consent was obtained in all cases. Local anesthesia consisted of $2 \%$ lidocaine injected subcutaneously with

Correspondence: Dr. Ranjit Sharma, Department of Cardiology, Shahid Gangalal National Heart Center, Bansbari, Kathmandu, Nepal. Phone: 9851013659, Email: sharmaranjit100@hotmail.com 
a 25 gauge needle and using a 22 gauge needle lidocine is introduced into deep tissue planes if needed. A $6 \mathrm{~F}$ sheath was used in most patients. Vascular sheath was flushed with normal saline after introduction, in between left and right coronary artery catheterization and after completion of the procedure. After completion of the procedure, the sheath was removed immediately, allowing a brisk backflow of blood to expel any clots. Data collection with statistical analysis were done using statistical package for social sciences version 13 for windows.

\section{RESULTS}

The right femoral approach was used in $92 \%$ of cases and the left in $8 \%$. Those patients who underwent radial route were excluded. Male $(65 \%)$ were exceeded the female and smoking (50\%) was the major predisposing factor (Table 1). Single-vessel disease was predominant (Table 2). The mean procedure time from initial puncture to withdrawal of the last catheter was $20 \pm 10$ minutes. However, no embolic or thrombotic event and vascular complications were occurred during and after procedure. There was no cerebrovascular accident, myocardial infarction, or iatrogenic left main stem dissection. The majority of patients $(90 \%)$ were discharged on the next day. Other were kept admitted as they were planed for intervention predischarge.

Table 1. Demographic and Clinical Characteristics in 100 Patients

\begin{tabular}{|lc|}
\hline Variable & Number of patients \\
\hline Mean age (years) & $65 \pm 10$ \\
Male & 68 \\
Female & 32 \\
Risk factors & \\
Smoking & 50 \\
Hypertension & 40 \\
Diabetes & 30 \\
Dyslipidemia & 20 \\
Positive family history & 5 \\
Indication for angiogram & \\
Positive stress test & 15 \\
Unstable angina & 45 \\
Stable angina & 10 \\
Postinfarction angina & 30 \\
Femoral approach & \\
\hline Right & 92 \\
Left & $8 \%$ \\
Previous femoral angiogram & 10 \\
\hline
\end{tabular}

Table 2. Angiographic Findings in 100 Patients

\begin{tabular}{|lc|}
\hline Finding & No of Patients \\
\hline Single-vessel disease & 30 \\
Double-vessel disease & 20 \\
Triple-vessel disease & 25 \\
Non Critical & 15 \\
Normal vessels & 10 \\
\hline
\end{tabular}

\section{DISCUSSION}

Our study didn't find any complication during or after the procedure. However there are reports of extensive analysis of the complications in more then 200,000 patients indicates the following: death $0.2 \%$, myocardial infarction $0.05 \%$, strok $0.07 \%$, arrrythmia $0.5 \%$ and major vascular complications less then $1 \%{ }^{7}$ So arterial access site bleeding accounts for the majority of complications encountered after cardiac catheterization. Populations at advance age, extreme body habits, bleeding diathesis and those receiving anticoagulant or antiplateles drugs are at greatest risk. ${ }^{8}$ Use of heparin during elective coronary angiogram may increase the risk of vascular complications. This was also seen in double-blinded randomized study which was conducted in India by a single operator. ${ }^{89}$ Hundred patients were randomized into two groups; patients received $2000 \mathrm{U}$ before CAG and placebo. However, no embolic or thrombotic event occurred in either group. The groin complication was seen in the patient who was randomized to heparin group. In this double blinded randomized study there was no advantage in using UFH.

The main limitation of our study was not having a control group. Therefore a study with larger group preferably with clinical trial would be needed to further support these findings.

\section{CONCLUSION}

In this study we did CAG without using heparin and there were no embolic or thrombotic event and vascular complications observed during or after procedure. So based on our findings and previous study we that routine elective CAG may be performed without the use of UFH found to be safe however further detail study is recommended.

\section{REFERENCES}

1. Rosamond W, Flegal K, Friday G, et al. "Heart disease and stroke statistics--2007 update: a report from the American Heart Association Statistics Committee and Stroke Statistics Subcommittee"Circulation 115 (5): e69 
2. Ahmad U, Frossard P. Coronary heart disease in South Asia: Need to redefine risk International Journal of Cardiology, $2006 \mathrm{Feb}$ 15;107(2):289-90

3. Scanlon PJ, Faxon DP, Audet AM, Carabello B, Dehmer GJ, Eagle KA, et al. ACC/AHA guidelines for coronary angiography: executive summary and recommendations. A report of the American College of Cardiology/American Heart Association Task Force on Practice Guidelines (Committee on Coronary Angiography) developed in collaboration with the Society for Cardiac Angiography and Interventions. Circulation. 1999; 99:2345-57.

4. Grossman's. Cardiac ctherization,angiography, and intervention. 7th ed. USA: Mosby; 2005.
5. Fransson SG, Nylander E. Vascular injury following cardiac catheterization, coronary angiography, and coronary angioplasty European Heart Journal 1994 15(2):232-235.

6. Niebauer J, Sixt S, zhang F, et al. Contemporary outcome of cardiac catheterizations in 1085 consecutive octogenarians International Journal of Cardiology;93(3):225-30.

7. Kern MJ.The cardiac catherization Handbook 3rd ed. USA: Mosby; 1999.

8. N Gautam, V Surase, S Karande, Is Heparin Necessary before Coronary Angiography. Indian heart journal 2001;5:51-2. 